\title{
Persistent Extratropical Regimes and Climate Extremes
}

\author{
Brian Hoskins $^{1,2}$ • Tim Woollings ${ }^{3}$
}

Published online: 12 July 2015

(C) The Author(s) 2015. This article is published with open access at Springerlink.com

\begin{abstract}
Some studies have suggested a recent increase in high-impact persistent circulation regimes in the extratropics. In this brief review paper, we discuss some aspects of this work and also consider more broadly how regimes such as blocking and stationary Rossby wave patterns may be altered under climate change. The amplified Arctic warming is discussed as one of several factors influencing the atmospheric dynamics from the equator to the poles. Some theoretical arguments are given alongside discussion of observational and modelling results. We include consideration of climate model skill and statistical aspects of the problem linking the distribution of climate variables to the extremes.
\end{abstract}

Keywords Climate extremes $\cdot$ Blocking $\cdot$ Rossby waves . Arctic warming

\section{Introduction}

Extreme events and months or seasons are the aspects of weather and climate that have impact on society and are consequently high in the demands of society from our science. Scientists are increasingly asked why events have occurred and if climate change is "the cause". The predictability of such

This article is part of the Topical Collection on Extreme Events

Brian Hoskins

b.hoskins@imperial.ac.uk

1 Meteorology, University of Reading, Reading, UK

2 Grantham Institute, Imperial College London, London, UK

3 Atmospheric, Oceanic and Planetary Physics, University of Oxford, Oxford, UK extremes is vital because of the possibility that some of the impacts could be avoided. In the extratropics, longer-term extremes are usually associated with the persistence of particular circulation regimes, and instantaneous extreme events are also often associated with such regimes (e.g. [1-5]).

The anomalous flow in a particular period can be viewed in a number of ways. As an example, Fig. 1 gives the average upper tropospheric stream function for a $270^{\circ}$ sector in the Northern Hemisphere for a 2 -week period. In one perspective in the eastern North Atlantic, the jet is strong and shifted to the north. This can also be interpreted from the regime perspective as a positive North Atlantic Oscillation (NAO) (and negative East Atlantic pattern) regime. Alternatively, it could be viewed as an amplified stationary Rossby wave pattern from the eastern N Pacific to Europe. Otherwise, the focus could be on the block that is developing over Europe. These differing perspectives are valid and complementary and can all be useful. In recent years, the focus has tended to be on fixed spatial patterns such as the NAO but there are now indications of increasing interest in all of these perspectives. The term "regime" has often been used to denote a fixed spatial flow pattern which attains some significance over and above the continuum of weather noise (e.g. [6]). However, in this review we use the term loosely to refer to a persistent anomalous flow which does not necessarily recur with the same pattern, including for example, wave trains with no preferred phase.

In the Regimes Under Projected Climate Change section, we will review some of the recent literature on regimes, jets and blocks under climate change. The Amplified Arctic Warming and Emerging Changes? section will focus on amplified Arctic warming and discussions of possible emerging changes that may be associated with them. With some latitude asked for by the authors, basic theory on possibly related stationary Rossby wave behaviour will also be given in this section. Recent work on waves and possible resonance will be covered in the Waves and Resonance section, and the 


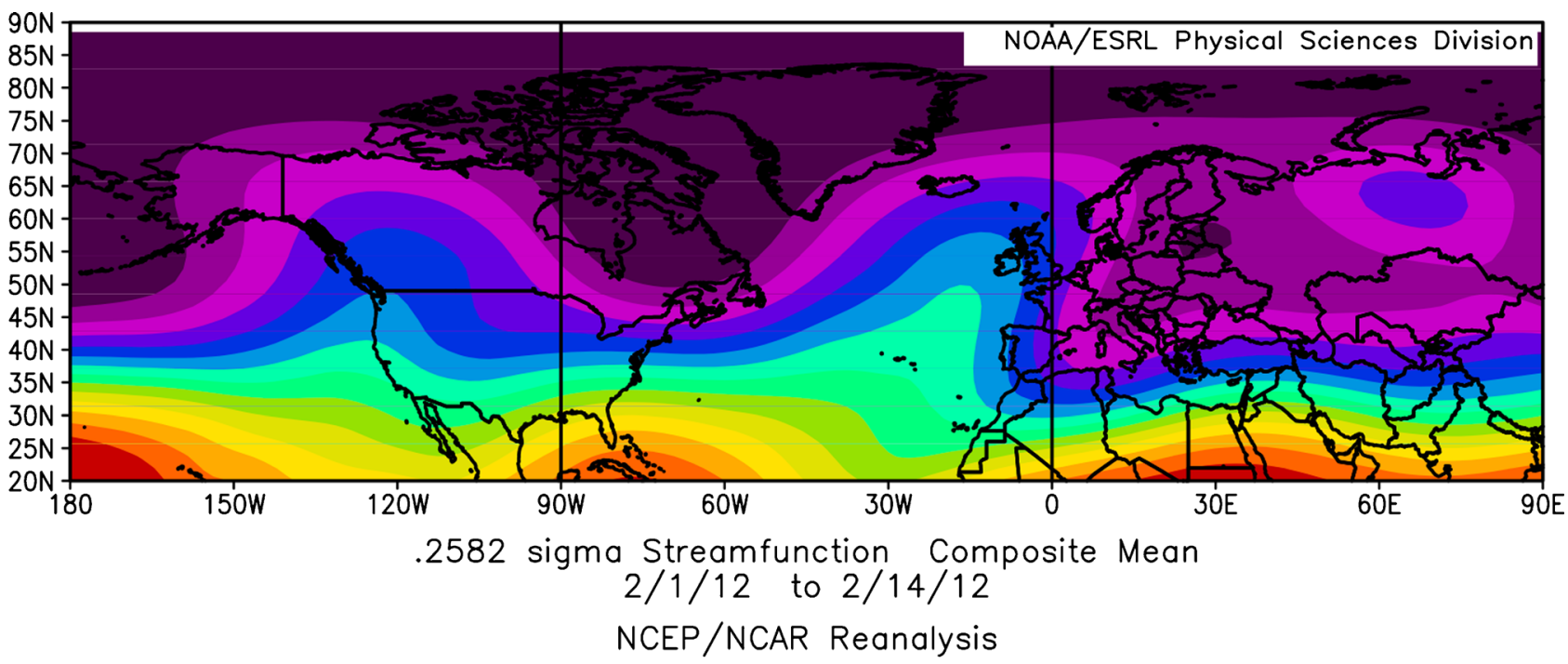

\begin{tabular}{llllll|l|l|l|l|l|l|}
\hline & & & & & & \\
\hline$-1.2 e+08$ & $-1 e+08$ & $-8 e+07$ & $-6 e+07$ & $-4 e+07$ & $-2 e+07$ & 0
\end{tabular}

Fig. 1 Composite upper tropospheric streamfunction $\left(\mathrm{m}^{2} \mathrm{~s}^{-1}\right)$ over a 2-week period in 2012 that was followed by severe cold over northern Europe

Extremes and PDF Statistics section reviews some recent papers on extremes and pdf statistics.

\section{Regimes Under Projected Climate Change}

Climate models are central to our understanding of how climate change affects blocking and other regimes. Before proceeding, it is vital to assess the skill of current models in simulating such regimes. Many current models still exhibit the historical biases towards overly zonal midlatitude flow, with excessively strong jets lying too far equatorwards and with cyclone intensities and blocking frequencies both underestimated [7, 8]. Even in the coupled model intercomparison project phase 5 (CMIP5) ensemble, several models reproduce very little winter blocking over Europe by some measures (e.g. [9]). Models can also exhibit significant biases in the level of planetary wave activity, although these are less systematic across different models [10]. In some models, however, the biases in blocking and other regimes have been much reduced, probably through a combination of increased vertical as well as horizontal model resolution and improved parameterisations [11-16]. This, along with encouraging evidence of seasonal prediction skill [17], suggests some degree of trustworthiness in the simulation of extratropical regimes in some climate models.

Some theoretical concepts have guided the interpretation of projected circulation changes, for example the effects of horizontal temperature gradients [18]. Motivated by simpler dynamical systems, Palmer [19] suggested that the change in circulation would largely occur through changes in the loading of the current dominant flow regimes. The projected circulation response does indeed often resemble the dominant patterns of variability, at least in the extratropics, although one counterexample is the baroclinic nature of the forced response as compared to the equivalent barotropic natural variability [20]. In the tropics, the forced response is generally quite different to the dominant ENSO-like variability [21], although we note that model responses in the tropical Pacific may not be trustworthy [22]. In general, changes are seen in the patterns of variability themselves, so that a more coupled picture emerges: the change in the mean state resembles the regimes, but then, the patterns of variability about this new state are altered [23]. Projected changes in the jet streams provide an example of this. Suppose the dominant mode of jet variability represents meridional jet shifts, as is often the case. The response to forcing is also generally a shift of the jet, so that the response does indeed project onto the leading pattern of variability. In the simplest case, the leading mode of variability remains a meridional shift but centred about the new climatological location of the jet. Hence, the Eulerian patterns of variability are shifted along with the jet. In practice, the behaviour can be more complicated than this, with models often predicting changes in the nature of the variability itself, for example from shifting towards pulsing of the jet [7].

Concerning blocking, a consensus is emerging of a general decrease in blocking occurrence under climate change. This signal is seen in CMIP3 [24] as well as CMIP5 models [9, 25] and also in high-resolution model experiments [26]. The blocking decrease can be reproduced diagnostically considering only the changes in the mean and variance of the zonal wind (Woollings [27], De Vries et al. [28]). For example, blocking decreases and shifts eastward over Europe which 
seems to be a consequence of the projected eastward extension of the jet and storm track (Woollings et al. [29], Haarsma et al. [30]). Reductions in blocking on the poleward flank of the jet are consistent with the projected poleward jet shift in many regions. These considerations suggest that blocking is responding somewhat passively to the changes in the largescale circulation. It does seem possible that blocking may change more "actively" in the future, for example due to changes in diabatic processes triggered by warmer sea surface temperatures (SSTs) (Croci-Maspoli and Davies [31]). Such a response does not appear to dominate blocking changes in current projections. However, better representations of physical and dynamical processes may be required for this mechanism, and it will be an important hypothesis to examine as models improve further. While a decrease in blocking alone is expected to reduce the global occurrence of extreme events, it is noteworthy that the eastward shift of European blocking leads to a local increase in blocking over Western Russia in many models, in particular in summer $[9,25]$.

Confidence in projected blocking changes is limited by model skill and by the lack of a theoretical basis for the changes. Despite this, however, we can have some confidence that we will see changes in the impact of blocking events. Masato et al. [32] showed that for the same circulation anomalies, surface temperature anomalies become weaker in future winter blocking events compared to the present day. This is largely due to a change in thermal advection. Wintertime horizontal temperature gradients are weakened due to both the land-sea warming contrast and the amplified warming in the Arctic. Hence, the anomalous thermal advection is weakened even if the wind anomalies are unchanged ([33-35], Schneider et al. [61]). The robustness of the spatial pattern of warming hence lends confidence to projected changes in temperature variability.

In the North Atlantic sector, the 2009/2010 winter was dominated by blocking and negative NAO conditions which led to widespread severe cold. However, there are indications that the cold was in fact less extreme than expected given the circulation anomalies [36]. This is likely due to the background warming signal more than changes in thermal advection, but it highlights that winter cold extremes are less likely to be a serious concern in the future. More concerning is the potential for summer heatwaves to be exacerbated by increasing temperature variability as well as the mean warming [37]. Possible changes in variance and higher statistical moments will be discussed below in the Extremes and PDF Statistics section.

\section{Amplified Arctic Warming and Emerging Changes?}

\section{Recent Research}

In the long-term projections described above, there is a wellknown conflict which limits the change in midlatitude circulation; in the lower troposphere the meridional temperature gradient decreases due to amplified Arctic warming, while in the upper troposphere it increases due to amplified tropical warming [38]. In recent years, the rapid Arctic warming has been conspicuous against the backdrop of the hiatus in global mean warming. Enhanced tropical upper tropospheric warming has been harder to detect until recently (e.g. [39]). The same period has been marked by several extreme weather events often linked to persistent circulation patterns [40], sparking suggestions that the Arctic warming might be the cause of this.

Cohen et al. [41] summarise several distinct hypotheses relating midlatitude circulation to Arctic warming. These hypotheses have certainly raised very important questions over how the variability of atmospheric circulation responds to forcing, since previous work in this area has been overly focused on fixed spatial patterns of variability such as the NAO. However, evidence to support these hypotheses is so far limited by the very short period in which amplified Arctic warming is believed to have affected the midlatitudes (e.g. [42]). Atmospheric variability is infamously noisy, and periods of several decades are generally needed to robustly identify trends (e.g. [43]). A second general point is that observational correlations as presented in many papers provide no evidence of a causal link between the Arctic and the midlatitudes. Such evidence must come from modelling studies, and this is lacking for some of the suggested mechanisms. Barnes and Screen [44] provide an overview of the contexts in which Arctic amplification can influence the general circulation, highlighting the most plausible mechanisms and the open questions.

Principal among the recent claims is the suggestion of Francis and Vavrus [45] that Arctic warming has already led to weakened westerly winds and hence more slowly moving and amplified wave patterns. In this and subsequent papers (e.g. [46]), some evidence is given of trends in planetary wave behaviour in line with this hypothesis. However, the significant trends are not robust across a range of different methods and are often limited in their geographical and seasonal coverage $[47,48]$. Recent trends in blocking activity are similarly lacking in significance [49]. Given the short time periods in question, model evidence will likely be crucial in determining the planetary wave response to Arctic warming. Hassanzadeh et al. [50] have led the field in this area with simple dynamical model experiments showing a reduction in wave amplitude as the meridional temperature gradient weakens, in contrast to the Francis and Vavrus hypothesis. Blocks are widely expected to thrive when there is a strong storm track upstream (e.g. $[51,52])$, and in line with this, Hassanzadeh et al.'s simulations show a decrease in blocking as the temperature gradient is weakened.

While there are few modelling studies of the changes in wave variability, many have reported on the mean state 
response to prescribed sea ice loss or Arctic warming. This generally comprises a robust but weak response towards the negative phase of the Northern Annular Mode or North Atlantic Oscillation. This is seen in a hierarchy of models from dry dynamical cores $[53,54]$ through more realistic atmosphere models (as reviewed by [55]) to state of the art coupled models [56] and has appeared in summer as well as winter (e.g. [57]). It is noteworthy that this response often comprises an equatorward shift of the jet which is often more pronounced than the jet weakening. Thermal wind balance is often cited as the mechanism linking Arctic warming to a weakened jet, and it is true that the perturbed climatological state will inevitably be in thermal wind balance. However, this state will generally have been shaped by a complex chain of eddy-mean flow feedbacks, often resulting in a meridional shift of the eddy-driven jet (see [58] for a relevant example). Hence, the first suggested link in the chain whereby Arctic warming leads to a weakened jet is itself not so clear. The jet shift is in general the dominant robust response to Arctic warming and in fact seems apparent in many circulation indices shown by Francis and Vavrus [46] for example. Consequences for planetary wave behaviour will ultimately depend on the waveguiding ability of the jet as influenced by its position as well as its width and speed [59]. The projected future jet changes vary considerably, depending on the region and season, as a result of multiple influences in addition to the Arctic warming (e.g. [60]).

Schneider et al. [61] provided some theoretical guidance on the response of synoptic waves to Arctic warming. As described in the Regimes Under Projected Climate Change section, this is dominated by the thermal advection effect whereby a weakened mean gradient leads to weakened temperature variance. This was supported by simulations in which the wave amplitude, characterised by an effective mixing length, appeared relatively unchanged. Reduced baroclinicity and temperature contrasts suggest reduced growth rates and wind and temperature anomaly magnitudes. From a different perspective, meridional parcel displacements, $L$, generally scale as the width of the baroclinic region. Therefore, if amplified Arctic warming reduces the polar side of the baroclinic region, it would tend to shift the storm track equatorwards and reduce $L$. However, if the baroclinicity is reduced over a broader latitudinal range, then the storm track latitude and $L$ could stay the same.

\section{Basic Theory Relevant to Stationary Rossby Wave Behaviour}

There seems to be little written on basic theoretical arguments for the expectations of changes associated with amplified Arctic warming. In this spirit, in this sub-section, we permit ourselves to give some implications for stationary Rossby waves, both free and forced, of the reductions in the magnitudes of middle latitude zonal flow and baroclinicity that might accompany such warming.

i. Stationary Rossby wavelength

The stationary Rossby wavenumber $K_{S}$ on a zonal flow $\bar{u}$ is given by $\bar{u}=\beta / K_{s}^{2}$, and so small changes in it and the stationary wavelength $L_{s}=2 \pi / K_{s}$ will satisfy:

$\frac{\delta L_{s}}{L_{s}}=-\frac{\delta K_{s}}{K_{s}}=\frac{1}{2} \frac{\delta \bar{u}}{\bar{u}}$

A $5 \%$ decrease in zonal flow would therefore lead to a $2 \frac{1}{2} \%$ increase in the stationary wavenumber and decrease in the stationary wavelength. For a zonal wavenumber 3 , this would be equivalent to only about a $250-\mathrm{km}$ decrease in the wavelength. It should be noted that weakening of the zonal flow does not necessarily lead to more stationarity overall; it just increases the wavenumber that becomes stationary.

The Rhines scale for the width of jets also $\sim L_{s}$, and so it will also decrease weakly with the flow speed as in Eq. 1. Seeing that the Earth is in a regime in which one or two jets are possible, this gives a slightly increased chance of a double-jet structure as the flow weakens.

ii. Stationary wave response to a large-scale mountain ridge, e.g. the Rockies

Scalings for the amplitude of the stationary Rossby wave response to a large-scale mountain may be obtained from vorticity arguments. Vortex shrinking due to orography of height $h$ will lead to a maximum vorticity reduction $\sim f h / H$, where $H$ is the depth of the troposphere. The meridional displacement of the absolute vorticity contours in the Rossby wave triggered by the mountain will be comparable to this. Therefore, the meridional displacement of a streamline, $L$, scales as $\beta L \sim f h / H$.

This gives the expectation that $L$ will be independent of the zonal wind. However, the temperature anomaly associated with this displacement, $T^{\prime}=-L \partial \bar{T} / \partial y$, will reduce with the baroclinicity,

$B=-\frac{g}{\bar{T}} \frac{\partial \bar{T}}{\partial y}=\frac{g}{\bar{\theta}} \frac{\partial \bar{\theta}}{\partial y}=f \frac{\partial \bar{u}}{\partial z}$.

iii. Stationary wave response to lower tropospheric midlatitude heating

As in Hoskins and Karoly [62], low-level heating, $Q$, is generally balanced by meridional advection of cold air:

$v^{\prime} \partial \bar{T} / \partial y \sim Q$ or $v^{\prime} \sim B^{-1} Q$.

Therefore, a reduced thermal gradient implies larger $v^{\prime}$. Using a zonal wind $u \sim \bar{u}$, the meridional slope of the 
stream function, $\alpha$, must then scale as $B^{-1} Q \bar{u}^{-1}$. Combining this with the zonal scale, which is taken to be $K_{s}^{-1}$, the amplitude of the streamline displacement then scales as

$$
L \sim \alpha K_{s}^{-1} \sim B^{-1} Q \bar{u}^{-1} K_{s}^{-1} .
$$

Using the definition of $K_{s}$

$L \sim B^{-1} Q \bar{u}^{-1 / 2}$,

and this implies that the temperature perturbation scales as

$T^{\prime} \sim Q \bar{u}^{-1 / 2}$.

Provided the lower tropospheric heating, such as that over the Gulf Stream, stays the same, then Eqs. 5 and 6 imply that with smaller $B$ and $\bar{u}$, the stream function displacement in the forced stationary Rossby wave would increase markedly, and even the temperature perturbations would increase weakly, with fractional changes behaving like those of $K_{s}$ in Eq. 1.

In summary, for decreased baroclinicity and zonal wind as a simple result of Arctic amplification, the arguments suggest the following:

- Slightly decreased stationary wavelength $\left(\sim \sim^{1 / 2}\right)$

- Slightly increased possibility of double jets with a slightly reduced Rhines scale $\left(\sim \bar{u}^{1 / 2}\right)$

- For Rossby waves forced by orography, the same streamline amplitude but decreased temperature anomaly $(\sim B)$

- For Rossby waves forced by the same midlatitude heating, a much increased streamline amplitude $\left(\sim B^{-1} \bar{u}^{-1 / 2}\right)$ and slightly increased temperature perturbation $\left(\sim \bar{u}^{-1 / 2}\right)$

It is the last of these that is perhaps the most interesting, but it depends on the low-level heating in, for example, the western boundary current regions staying the same magnitude. Given the importance of individual storms in the net heating and the fact that these storms can be expected to have growth rates decreasing with $B$, then perhaps, this seems unlikely. However, in a warmer world with more moisture availability, the tendency for increased latent heat release over western boundary currents could compensate the weaker baroclinicity effect on storms to give little net change in the heating.

The real world may be a lot more complicated than suggested by the results discussed here, which are dependent on simple changes in the midlatitude flow produced by amplified polar warming. For example, there may be increased baroclinicity in the upper troposphere. Given the equivalent barotropic nature of the arguments in (i) and (ii), this might be expected to decrease the small changes expected in stationary wavelength and orographically forced waves. However, it is unlikely to reduce the amplified response to low-level heating discussed in (iii). Another important complexity in the real world may be changes in subtropical winds and tropical wavedriving [63-65].

\section{Waves and Resonance}

Several recent studies focus on potential planetary or Rossby wave changes. Two complimentary perspectives have been taken, and their relative merits remain a live issue. One considers a latitude circle and the planetary waves around it. The other perspective is of Rossby waves with propagation along tracks that curve westwards in or out of the tropics and with guiding in strong westerly jets in the higher latitudes. In the first, the cyclic nature of the sphere is crucial, whereas in the second, it is not.

From the Rossby wave perspective, Ding et al. [66] found that a portion of the Southern Annular Mode (SAM) appears to be associated with a Rossby wave train triggered in the tropical South-Eastern Pacific. (They contrasted the mechanism for this portion of the SAM with that in the Indian Ocean, where internal dynamics appears to be dominant.) For the Northern Hemisphere, Ding et al. [67] ascribed recent winter warm anomalies over NE Canada and Greenland, with a strong NAO flavour, to a Rossby wave propagating from the tropical North Pacific. Lee et al [68] ascribed Arctic amplification to be mainly associated with the heat flux associated with stationary waves as well as circumglobal patterns triggered on intraseasonal timescales by enhanced Indian Ocean convection.

In the other direction, a distinct regional influence has also been suggested of Barents-Kara sea ice on Eurasian winter blocking [69-71]. As before, the observational correlations are only weakly supported by modelling evidence. For example, only a couple of CMIP5 models might support this link in their natural variability [72], although the direction of causality could be opposite [73]. While Mori et al [74] achieved a circulation response to sea ice forcing that clearly resembles observations, its magnitude is considerably weaker.

Several studies have suggested Rossby wave propagation as the mechanism by which the Arctic change influences Eurasia, although a stratospheric pathway is also possible via changes in upwards propagating wave activity and subsequent descending Northern Annular Mode anomalies [75, 76]. In general, however, Rossby waves are triggered much more readily by lower-latitude deep convection rather than by higher-latitude boundary layer processes [77]. In line with this, several studies argue that the polar anomalies are driven from lower latitudes, rather than vice versa. For example, Sato et al [78] presented a Rossby wave train originating over the Gulf Stream which warmed the Barents-Kara Sea through 
downwards surface heat fluxes and then arched south leading to high pressure over Eurasia.

From the alternative zonal perspective, Petoukhov et al [79] discussed the idea that some recent Northern Hemisphere summers with large anomalies may have been due to resonance in zonal wavenumbers 6-8. Coumou et al [80] produced further information on this possibility. Screen and Simmonds [81] discussed the large amplitudes found in some zonal wavenumbers in the band 3-8 in some seasons with highimpact anomalies. Of course, Fourier analysis of any isolated local structure will give amplitudes in a range of zonal wavenumbers (e.g. the transform of a delta function in the extreme case). Hence, in any season with large-amplitude anomalies in at least one sector of the hemisphere, large amplitudes in some zonal wavenumbers are inevitable. However, the implication of Petoukhov et al. [79] and Coumou et al. [80] is that extreme seasons can be associated with large-amplitude anomalous wave-like structures which extend around the hemisphere.

Manola et al. [59] discussed the ability of idealised zonal jets to trap and guide Rossby waves. They found that this is most likely in narrow fast jets and that the Austral summer provides the most likely candidate for this. In contrast, Petoukhov et al. [79] and Coumou et al. [80] considered the possibility that Rossby waves can sometimes be trapped in a hemispheric waveguide in the Northern Hemisphere in summer. Focussing on the zonally averaged jet, they suggested that the conditions for guiding stationary waves around the hemisphere and therefore the possibility of "quasi-resonance" of forced and free wavenumbers $6-8$ were found in some recent Northern Hemisphere summers with large anomalies. They indicated that Arctic-amplified warming may be implicated. However, the existence of a turning latitude (at which the wave is reflected) on the poleward flank of the jet is usual, and it is the existence of such a latitude on the subtropical flank that is vital for the creation of a waveguide. In the analysis of Petoukhov et al. [79], it is actually the sharpness of the tropical side of the subtropical jet that was crucial to produce a waveguide between about $35^{\circ}$ and $47^{\circ} \mathrm{N}$. Perhaps, tropical broadening could be important in this regard.

The ability of the time-mean longitudinally varying westerly flow to trap and guide stationary Rossby waves was previously studied by Hoskins and Ambrizzi [82] and Branstator [83] for Northern Hemisphere winter and Ambrizzi et al. [84] for summer. Hoskins and Ambrizzi [82] and Ambrizzi et al. [84] found that the Northern Hemisphere jets in winter and summer can guide waves with a range of wavenumbers. Figure 2, which is based on Figs. 13 and 17 of [84], summarises the propagation of stationary waves and shows the waveguides (double-shafted arrows). The very steady strong summer westerly jet across Asia, on the northern side of the Tibetan Plateau, acts as a good guide for Rossby waves, and Enomoto et al. [85] associated the formation of the Bonin high north of Japan with the breaking of such waves in that region.
Indeed, as seen in Fig. 2, all the waveguides are of limited length and waves will tend to arch equatorwards at their exits (the curved single-shafted arrows). Branstator [83] also found this behaviour but suggested that the slowly varying theory underlying some of the analysis of Hoskins and Ambrizzi [82] can lead to an underestimation of the ability of waves to communicate around the hemisphere. However, even then the possibility of the downstream waves significantly reinforcing the upstream part of the wave train, leading to real, rather than quasi, resonance, appeared to be low.

Considering changes that may have already occurred or are likely in the future, in general, weaker jets, if indeed realised, would tend to reduce the expectation of waveguiding by them. However, any zonal wind curvature increases in the subtropical region, particularly in the "leaky" weak jet regions, would be important.

\section{Extremes and PDF Statistics}

Weather and climate extremes are associated with the wings of the pdfs of the relevant variables. These wings are very dependent on the mean and the higher moments of the pdfs. In the last few years, there has been increasing interest in the nature of these higher moments and whether any changes in them are likely to be important in the future occurrence of extremes.

Simolo et al. [86] analysed 50 years of European station data for daily maximum and minimum temperatures, $T_{\max }$ and $T_{\min }$. The largest non-Gaussian behaviour was in $T_{\min }$ which was skewed to low temperatures. The fourth moment, the kurtosis, is indicative of the fatness of the tails. It was less than the Gaussian for $T_{\max }$ and greater than the Gaussian for $T_{\min }$. Since no separation was made between summer and winter, physical arguments for these results are problematic. Indications of change in variance over the period were found to occur only locally, and in general, the change in mean dominated the changing distributions. This contrasted with the earlier studies of Della-Marta et al. [87] and Parey et al. [88] that found important increases in variance in summer $T_{\max }$ in Europe, with the latter also suggesting this for $T_{\min }$ in winter. Global gridded daily $T_{\max }$ and $T_{\min }$ data were analysed by Donat and Alexander [89] so as to compare their pdfs in the two 30-year periods before and after 1980. They also found that shifts in the means dominated. Variance changes were not spatially coherent, but in general, the skewness towards low temperatures reduced during the second period. Hansen et al. [90] focussed on daily mean temperatures for the same period, and they did consider the two solstitial seasons separately. Their analysis suggested that the variability in each season had mostly increased from the early to the late period. However, this change was halved if the data was detrended, and Rhines and Huybers [91] pointed out that if issues related to 
Fig. 2 Stationary wavenumber $K_{s}$, following Hoskins and Karoly [77], for the climatological period 1981-2010 using the NCEP-

NCAR reanalysis. $K_{s}$ is plotted only where real, and note that the colour bar saturates for values greater than 8 , especially in the tropical and polar regions. The waveguides are highlighted by double arrows and other preferred wave paths with single arrows.

These are taken from Hoskins and Ambrizzi [82] and Ambrizzi et al. [84]

\section{DJF}

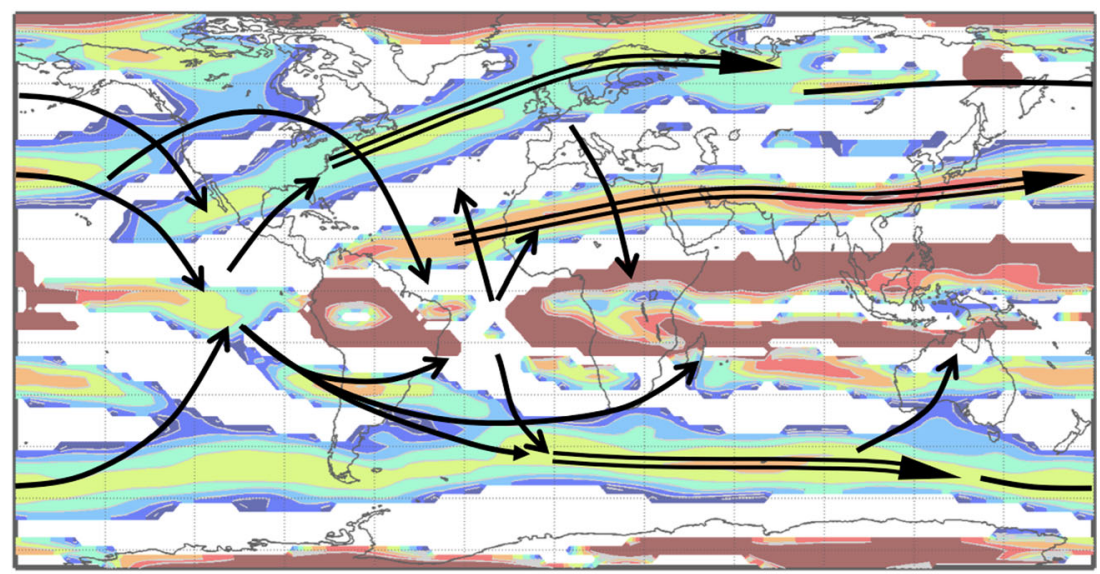

JJA
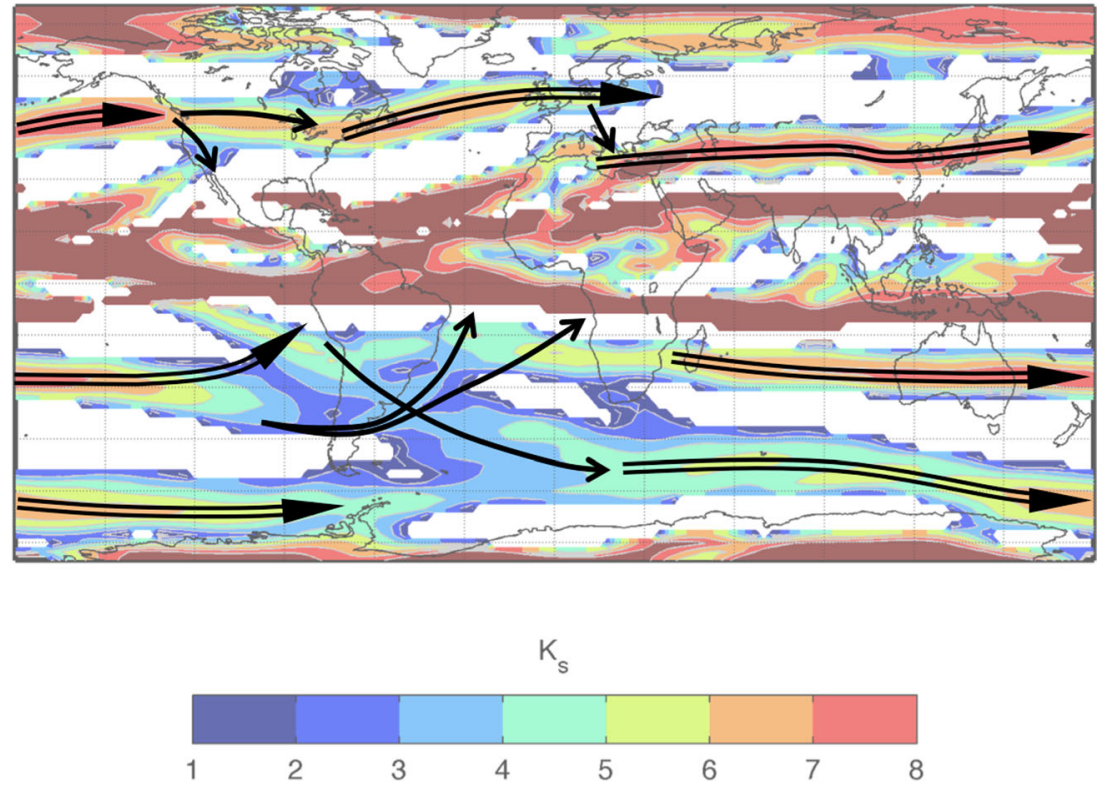

statistical analysis in the presence of nonlinear trends in the mean and changes in surface-station density are considered, there is little evidence of a change in variance, though the change in heat extremes found by Hansen et al. [90] due to increases in the mean temperature remains very clear.

To improve confidence in projected changes in extremes, it is important that the shapes of the distributions of climate variables are well understood and related to physical processes. For example, given amplified low-level warming in the Arctic, the origin of much of the extreme cold air in middle latitudes in winter, a reasonable hypothesis is for a relative reduction in the cold tail of winter temperatures. In a hot summer in middle latitudes, such as that in Europe in 2003, the drying of the soil and the consequent decrease in the balancing of solar heating by evaporation and increase in the sensible heating [92] suggests a hypothesis of an extended warm tail in summer temperatures. Increased variance could also occur due to an increase in the land-sea temperature contrast [34]. The earlier studies reviewed above suggested such increased variance in a particular region, but it has not been found to occur in general.

A comprehensive understanding remains to be reached, but some recent progress has been made.

Ruff and Neelin [93] examined the Gaussianity of pdfs of local daily surface temperature max, min and average. In many areas, they found tails that were fatter than Gaussian. They associated these with the importance of advection in regions of significant temperature gradient, a process that gives a much fatter exponential tail. They emphasised the interesting point that, though a fat tail implies the more frequent occurrence of extremes than in a Gaussian distribution, it also implies less change in extremes for a simple shift of the mean in a changing climate. Posing a model for SST composed of a stochastic process with multiplicative noise, Sura 
and Sardeshmukh [94] determined a relationship between the third and fourth moments of the distribution. They showed that their relationship is in remarkable agreement with that derived from observed SST data. Also, Luxford and Woollings [95] suggested that some of the skewness and kurtosis of flow fields is a simple consequence of taking an Eulerian perspective in the presence of localised features such as the jet streams.

The changing occurrence according to CMIP5 models of cold air outbreaks, defined as two or more winter days with the temperature at least two standard deviations below normal, was examined by Gao et al. [96]. They found that the dominant impact was through the shift in the mean temperature. However, changes in standard deviation contributed to around $20 \%$ of the decrease in cold air outbreaks. In some regions, changes in the skewness were also found to be of similar importance. They thought that these changes could be associated with asymmetries in thermal processes near ice and snow boundaries or perhaps with changes in blocking,

In contrast, Schneider et al. [61] considered pdfs of 3- to 15-day timescale temperature anomalies at $850 \mathrm{hPa}$ and showed that they were remarkably Gaussian out to their tails. They attributed this to the dominance of synoptic eddy turbulence.

To conclude, no clear picture of changes in weather and climate extremes has yet emerged, and it is to be hoped that future research, based on physical and theoretical arguments and on observed and modelled data, will provide more insight into the details of the statistical distributions of climate variables, including how they have changed and may change in the future.

\section{Concluding Comments}

Considerable progress has been made in recent years in understanding persistent extratropical circulation regimes. Several different perspectives have been taken, for example focused on jet stream variability, blocking, Rossby wave propagation or on clustering approaches. All of these perspectives are useful and complementary in understanding extratropical variability.

There have also been significant advances in our understanding of climate extremes, both in terms of the dynamics and also how the extremes relate to the pdfs of climate variables. This highlights the importance of understanding the physics of the basic state as well as the response to forcing. In particular, a thorough understanding of the physics governing the shape of distributions should be a priority.

Despite these advances, there are strong societal drivers for more progress to be made. Particular interest centres on attribution questions such as whether regimes and/or extremes have been changing recently, and if so, why and what changes in them can be expected in the future for various greenhouse gas scenarios. This progress will be achieved through a combination of observational diagnosis and a hierarchy of modelling experiments. Climate models have improved to the point that some models now have a reasonable simulation of midlatitude circulation regimes. This makes them valuable tools to investigate the dynamical response to forcing. Some projected changes, such as a future decrease in blocking, are robust between models. However, a deeper understanding of the physics of blocking and its response to forcing are needed to enhance the confidence in results such as this.

Rapid changes such as the recent Arctic warming pose a particular challenge for identifying any potentially forced signal from the natural variability. Hence, in this situation, there might be particular benefit to be obtained from dynamical considerations, rooted as much as possible in theory as well as in the hierarchy from simple up to state of the art models.

Open Access This article is distributed under the terms of the Creative Commons Attribution 4.0 International License (http:// creativecommons.org/licenses/by/4.0/), which permits unrestricted use, distribution, and reproduction in any medium, provided you give appropriate credit to the original author(s) and the source, provide a link to the Creative Commons license, and indicate if changes were made.

\section{References}

1. Buehler T, Raible CC, Stocker TF. The relationship of winter season North Atlantic blocking frequencies to extreme cold or dry spells in the ERA-40. Tellus A. 2011;63:212-22.

2. Franzke CL. Persistent regimes and extreme events of the North Atlantic atmospheric circulation. Philos Trans R Soc A Math Phys Eng Sci. 2013;371(1991):20110471.

3. Mahlstein I, Martius O, Chevalier C, Ginsbourger D. Changes in the odds of extreme events in the Atlantic basin depending on the position of the extratropical jet. Geophys Res Lett. 2012;39: L22805.

4. Pfahl S, Wernli H. Quantifying the relevance of atmospheric blocking for co-located temperature extremes in the Northern Hemisphere on (sub-)daily time scales. Geophys Res Lett. 2012;39:L12807.

5. Sillmann J, Croci-Maspoli M, Kallache M, Katz RW. Extreme cold winter temperatures in Europe under the influence of North Atlantic atmospheric blocking. J Clim. 2011;24(22):5899-913.

6. Cheng X, Wallace JM. Cluster analysis of the Northern Hemisphere wintertime $500-\mathrm{hPa}$ height field: spatial patterns. J Atmos Sci. 1993;50(16):2674-96.

7. Barnes EA, Polvani LM. Response of the midlatitude jets and of their variability to increased greenhouse gases in the CMIP5 models. J Clim. 2013;26:7117-35. doi:10.1175/JCLI-D-1200536.1 .

8. Zappa G, Shaffrey LC, Hodges KI. The ability of CMIP5 models to simulate North Atlantic extratropical cyclones. J Clim. 2013;26: 5379-96.

9. Masato G, Hoskins BJ, Woollings T. Winter and summer Northern Hemisphere blocking in CMIP5 models. J Clim. 2013;26:7044-59.

10. Lucarini V, Calmanti S, Dell'Aquila A, Ruti PM, Speranza A. Intercomparison of the northern hemisphere winter mid-latitude 
atmospheric variability of the IPCC models. Clim Dyn. 2007;28(78):829-48.

11. Anstey JA, Davini P, Gray LJ, Woollings TJ, Butchart N, Cagnazzo C, et al. Multi-model analysis of Northern Hemisphere winter blocking: model biases and the role of resolution. J Geophys Res Atmos. 2013;118:3956-71.

12. Berckmans J, Woollings T, Demory ME, Vidale PL, Roberts M. Atmospheric blocking in a high resolution climate model: influences of mean state, orography and eddy forcing. Atmos Sci Lett. 2013;14:34-40.

13. Dawson A, Palmer TN. Simulating weather regimes: impact of model resolution and stochastic parameterization. Clim Dyn. 2014;44:2177-93.

14. Jung T, Balsamo G, Bechtold P, Beljaars A, Koehler M, Miller M, et al. The ECMWF model climate: recent progress through improved physical parametrizations. Q J Roy Meteorol Soc. 2010;136:1145-60.

15. Scaife AA, Copsey D, Gordon C, Harris C, Hinton T, Keeley S, et al. Improved Atlantic winter blocking in a climate model. Geophys Res Lett. 2011;38:L23703.

16. Williams KD, Harris CM, Bodas-Salcedo A, Camp J, Comer RE, Copsey D, et al. The Met Office Global Coupled model 2.0 (GC2) configuration. Geosci Model Dev Discuss. 2015;8:521-65. doi:10. 5194/gmdd-8-521-2015.

17. Scaife AA, Arribas A, Blockley E, Brookshaw A, Clark RT, Dunstone N, et al. Skillful long-range prediction of European and North American winters. Geophys Res Lett. 2014;41(7):2514-9.

18. Held IM. Large-scale dynamics and global warming. Bull Am Meteorol Soc. 1993;74:228-41.

19. Palmer TN. A nonlinear dynamical perspective on climate prediction. J Clim. 1999;12(2):575-91.

20. Woollings T. Vertical structure of anthropogenic zonal-mean atmospheric circulation change. Geophys Res Lett. 2008;35:L19702.

21. Lu J, Chen G, Frierson DMW. Response of the zonal mean atmospheric circulation to El Nino versus global warming. J Clim. 2008;21:5835-51.

22. Shin SI, Sardeshmukh PD. Critical influence of the pattern of tropical ocean warming on remote climate trends. Clim Dyn. 2011;36(7-8):1577-91.

23. Branstator G, Selten F. "Modes of variability" and climate change. J Clim. 2009;22(10):2639-58.

24. Barnes EA, Slingo J, Woollings T. A methodology for the comparison of blocking climatologies across indices, models and climate scenarios. Clim Dyn. 2012;38(11-12):2467-81.

25. Dunn-Sigouin E, Son S-W. Northern Hemisphere blocking frequency and duration in the CMIP5 models. J Geophys Res Atmos. 2013;118:1179-88.

26. Matsueda M, Mizuta R, Kusunoki S. Future change in wintertime atmospheric blocking simulated using a $20-\mathrm{km}-\mathrm{mesh}$ atmospheric global circulation model. J Geophys Res-Atmos. 2009;114:D12.

27. Woollings T. Dynamical influences on European climate: an uncertain future. Phil Trans R Soc A. 2010;368:3733-56.

28. De Vries H, Woollings TJ, Haarsma RJ, Hazelerger W. Atmospheric blocking and its relation to jet changes in a future climate. Cl Dyn. 2013;14:2643-54.

29. Woolings T, Gregory JM, Pinto JG, Reyers M, Brayshaw DJ. Response of the North Atlantic storm track to climate change shaped by ocean-atmosphere coupling. Nat Geosci. 2012;5:313-7.

30. Haarsma RJ, Selten FM, van Oldenborg GJ. Anthropogenic changes of the therma: and zonal flow structure over western Europe and eastern North Atlantic in CMIP3 and CMIP5 models. Cl Dyn 2013: 41:2577-88.

31. Croci-Maspoli M, Davies HC. Key dynamical features of the 2005/ 6 European winter. Mon Wea Rev. 2009;137:644-78.
32. Masato G, Woollings T, Hoskins BJ. Structure and impact of atmospheric blocking over the Euro-Atlantic region in present day and future simulations. Geophys Res Lett. 2014;41:1051-8.

33. De Vries H, Haarsma RJ, Hazeleger W. Western European cold spells in current and future climate. Geophys Res Lett. 2012;39: L04706.

34. Holmes C, Woollings TJ, de Vries H, Hawkins E. Robust changes in temperature variability under greenhouse gas forcing and the relationship with thermal advection. J Clim. 2015; in press.

35. Screen JA. Arctic amplification decreases temperature variance in northern mid- to high-latitudes. Nat Clim Chang. 2014;4:577-82.

36. Cattiaux J, Vautard R, Cassou C, Yiou P, Masson-Delmotte V, Codron F. Winter 2010 in Europe: a cold extreme in a warming climate. Geophys Res Lett. 2010;37:L20704.

37. Schär C, Vidale PL, Lüthi D, Frei C, Häberli C, Liniger MA, et al. The role of increasing temperature variability in European summer heatwaves. Nature. 2004;427(6972):332-6.

38. Rind $\mathrm{D}$. The consequences of not knowing low- and high-latitude climate sensitivity. Bull Am Meteorol Soc. 2008;89:855-64.

39. Allen RJ, Sherwood SC. Warming maximum in the tropical upper troposphere deduced from thermal winds. Nat Geosci. 2008;1(6): 399-403.

40. Coumou D, Rahmstorf S. A decade of weather extremes. Nat Clim Chang. 2012;2(7):491-6.

41. Cohen J, Screen JA, Furtado JC, Barlow M, Whittleston D, Coumou D, et al. Recent Arctic amplification and extreme midlatitude weather. Nat Geosci. 2014;7(9):627-37.

42. Overland JE, Wang M. Large-scale atmospheric circulation changes are associated with the recent loss of Arctic sea ice. Tellus A. 2010;62(1):1-9.

43. Deser C, Phillips A, Bourdette V, Teng H. Uncertainty in climate change projections: the role of internal variability. Clim Dyn. 2012;38(3-4):527-46.

44. Barnes EA, Screen JA. The impact of Arctic warming on the midlatitude jet-stream: Can it? Has it? Will it? Wiley Interdiscip Rev Clim Chang. 2015;6(3):277-86.

45. Francis JA, Vavrus SJ. Evidence linking Arctic amplification to extreme weather in mid-latitudes. Geophys Res Lett. 2012;39: L06801.

46. Francis JA, Vavrus SJ. Evidence for a wavier jet stream in response to rapid Arctic warming. Environ Res Lett. 2015;10(1):014005.

47. Barnes EA. Revisiting the evidence linking Arctic amplification to extreme weather in midlatitudes. Geophys Res Lett. 2013;40:4728 33.

48. Screen JA, Simmonds I. Exploring links between Arctic amplification and mid-latitude weather. Geophys Res Lett. 2013;40:959-64.

49. Barnes EA, Dunn-Sigouin E, Masato G, Woollings T. Exploring recent trends in Northern Hemisphere blocking. Geophys Res Lett. 2014;41(2):638-44.

50. Hassanzadeh P, Kuang Z, Farrell BF. Responses of midlatitude blocks and wave amplitude to changes in the meridional temperature gradient in an idealized dry GCM. Geophys Res Lett. 2014;41(14):5223-32.

51. Hoskins BJ, James IN, White GH. The shape, propagation and mean-flow interaction of large-scale weather systems. J Atmos Sci. 1983;40(7):1595-612.

52. Shutts GJ. The propagation of eddies in diffluent jetstreams: eddy vorticity forcing of 'blocking' flow fields. Q J R Meteorol Soc. 1983;109:737-61.

53. Butler AH, Thompson DW, Heikes R. The steady-state atmospheric circulation response to climate change-like thermal forcings in a simple general circulation model. J Clim. 2010;23:3474-96.

54. Lorenz DJ, DeWeaver ET. Tropopause height and zonal wind response to global warming in the IPCC scenario integrations. J Geophys Res-Atmos. 2007;112:D10119. 
55. Bader J, Mesquita MD, Hodges KI, Keenlyside N, Østerhus S, Miles M. A review on Northern Hemisphere sea-ice, storminess and the North Atlantic Oscillation: observations and projected changes. Atmos Res. 2011;101(4):809-34.

56. Deser C, Tomas RA, Sun L. The role of ocean-atmosphere coupling in the zonal-mean atmospheric response to Arctic sea ice loss. J Clim. 2015;28:2168-2186.

57. Petrie RE, Shaffrey LC, Sutton RT. Atmospheric response in summer linked to recent Arctic sea ice loss. Q J R Meteorol Soc. 2015. doi:10.1002/qj.2502.

58. Strong C, Magnusdottir G. The role of Rossby wave breaking in shaping the equilibrium atmospheric circulation response to North Atlantic boundary forcing. J Clim. 2010;23(6):1269-76.

59. Manola I, Selten F, Vries H, Hazeleger W. "Waveguidability" of idealized jets. J Geophys Res: Atmos. 2013;118(18):10-432.

60. Simpson IR, Shaw TA, Seager R. A diagnosis of the seasonally and longitudinally varying midlatitude circulation response to global warming*. J Atmos Sci. 2014;71(7):2489-515.

61. Schneider T, Bischoff T, Płotka H. Physics of changes in synoptic midlatitude temperature variability. J Clim. 2015;28:2312-31.

62. Hoskins BJ, Karoly D. The steady linear response of a spherical atmosphere to thermal and orographic forcing. J Atmos Sci. 1981;38:1179-96.

63. Brandefelt J, Körnich H. Northern Hemisphere stationary waves in future climate projections. J Clim. 2008;21(23):6341-53.

64. Haarsma RJ, Selten F. Anthropogenic changes in the Walker circulation and their impact on the extra-tropical planetary wave structure in the Northern Hemisphere. Clim Dyn. 2012;39(7-8):178199

65. Wang L, Kushner PJ. Diagnosing the stratosphere-troposphere stationary wave response to climate change in a general circulation model. J Geophys Res-Atmos (1984-2012). 2011;116:D16113.

66. Ding Q, Steig EJ, Battisti DS, Wallace JM. Influence of the tropics on the Southern Annular Mode. J Clim. 2012;25(18):6330-48.

67. Ding Q, Wallace JM, Battisti DS, Steig EJ, Gallant AJ, Kim HJ, et al. Tropical forcing of the recent rapid Arctic warming in northeastern Canada and Greenland. Nature. 2014;509(7499):209-12.

68. Lee S, Gong T, Johnson N, Feldstein SB, Pollard D. On the possible link between tropical convection and the Northern Hemisphere Arctic surface air temperature change between 1958 and 2001. J Clim. 2011;24(16):4350-67.

69. Honda M, Inoue J, Yamane S. Influence of low Arctic sea-ice minima on anomalously cold Eurasian winters. Geophys Res Lett. 2009;36:L08501.

70. Liu J, Curry JA, Wang H, Song M, Horton RM. Impact of declining Arctic sea ice on winter snowfall. Proc Natl Acad Sci. 2012;109(11):4074-9.

71. Petoukhov V, Semenov VA. A link between reduced Barents-Kara sea ice and cold winter extremes over northern continents. J Geophys Res-Atmos (1984-2012). 2010;115:D21111.

72. Woollings T, Harvey B, Masato G. Arctic warming, atmospheric blocking and cold European winters in CMIP5 models. Environ Res Lett. 2014;9:014002.

73. Woods C, Caballero R, Svensson G. Large-scale circulation associated with moisture intrusions into the Arctic during winter. Geophys Res Lett. 2013;40(17):4717-21.

74. Mori M, Watanabe M, Shiogama H, Inoue J, Kimoto M. Robust Arctic sea-ice influence on the frequent Eurasian cold winters in past decades. Nat Geosci. 2014;7:869-73.

75. Cohen JL, Furtado JC, Barlow MA, Alexeev VA, Cherry JE. Arctic warming, increasing snow cover and widespread boreal winter cooling. Environ Res Lett. 2012;7(1):014007.
76. Kim BM, Son SW, Min SK, Jeong JH, Kim SJ, Zhang X, et al. Weakening of the stratospheric polar vortex by Arctic sea-ice loss. Nat Commun. 2014;5:4646.

77. Hoskins BJ, Karoly DJ. The steady linear response of a spherical atmosphere to thermal and orographic forcing. J Atmos Sci. 1981;38(6):1179-96.

78. Sato K, Inoue J, Watanabe M. Influence of the Gulf Stream on the Barents Sea ice retreat and Eurasian coldness during early winter. Environ Res Lett. 2014;9(8):084009.

79. Petoukhov V, Rahmstorf S, Petri S, Schellnhuber HJ. Quasiresonant amplification of planetary waves and recent Northern Hemisphere weather extremes. Proc Natl Acad Sci. 2013;110(14):5336-41.

80. Coumou D, Petoukhov V, Rahmstorf S, Petri S, Schellnhuber HJ. Quasi-resonant circulation regimes and hemispheric synchronization of extreme weather in boreal summer. Proc Natl Acad Sci. 2014;111(34):12331-6.

81. Screen JA, Simmonds I. Amplified mid-latitude planetary waves favour particular regional weather extremes. Nat Clim Chang. 2014;4:704-9.

82. Hoskins BJ, Ambrizzi T. Rossby wave propagation on a realistic longitudinally varying flow. J Atmos Sci. 1993;50(12):1661-71.

83. Branstator G. Circumglobal teleconnections, the jet stream waveguide, and the North Atlantic Oscillation. J Clim. 2002;15(14): 1893-910.

84. Ambrizzi T, Hoskins BJ, Hsu HH. Rossby wave propagation and teleconnection patterns in the austral winter. J Atmos Sci. 1995;52(21):3661-72.

85. Enomoto T, Hoskins BJ, Matsuda Y. The formation mechanism of the Bonin high in August. Q J R Meteorol Soc. 2003;129(587): $157-78$.

86. Simolo C, Brunetti M, Maugeri M, Nanni T. Evolution of extreme temperatures in a warming climate. Geophys Res Lett. 2011;38: L16701.

87. Della-Marta PM, Haylock MR, Luterbacker J, Wanner H. Doubled length of western European summer heat waves since 1880. J Geophys Res-Atmos. 2007;112, D15103.

88. Parey S, Dacunha-Castelle D, Huong Hoang TT. Mean and variance evolutions of the hot and cold temperatures in Europe. Clim Dyn. 2010;34:345-9.

89. Donat MG, Alexander LV. The shifting probability distribution of global daytime and night-time temperatures. Geophys Res Lett. 2012;39(14):L14707.

90. Hansen J, Sato M, Ruedy R. Perception of climate change. Proc Natl Acad Sci U S A. 2012;109(37):E2415-23.

91. Rhines A, Huybers P. Frequent summer temperature extremes reflect changes in the mean, not the variance. Proc Natl Acad Sci. 2013;110(7):E546.

92. Fischer EM, Schär C. Future changes in daily summer temperature variability: driving processes and role for temperature extremes. Clim Dyn. 2009;33(7-8):917-35.

93. Ruff TW, Neelin JD. Long tails in regional surface temperature probability distributions with implications for extremes under global warming. Geophys Res Lett. 2012;39(4).

94. Sura P, Sardeshmukh PD. A global view of non-Gaussian SST variability. J Phys Oceanogr. 2008;38(3):639-47.

95. Luxford F, Woollings T. A simple kinematic source of skewness in atmospheric flow fields. J Atmos Sci. 2012;69(2):578-90.

96. Gao Y, Leung LR, Lu J, Masato G. Persistent cold air outbreaks over North America in a warming climate. Environ Res Lett. 2015;10:044001. doi:10.1088/1748-9326/10/4/044001. 